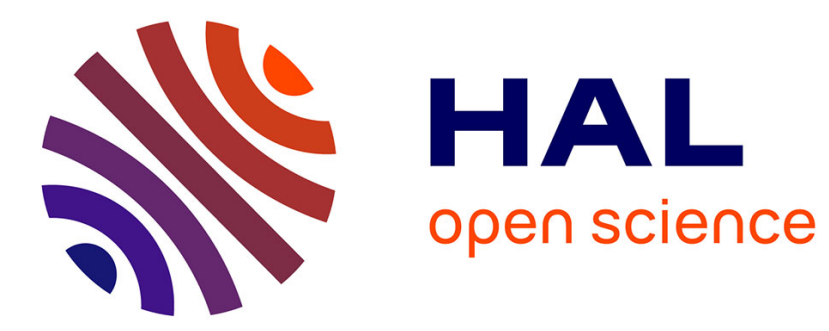

\title{
Convenient synthesis of cobalt nanoparticles for the hydrogenation of quinolines in water
}

Julien Hervochon, Vincent Dorcet, Kathrin Junge, Matthias Beller, Cedric Fischmeister

\section{- To cite this version:}

Julien Hervochon, Vincent Dorcet, Kathrin Junge, Matthias Beller, Cedric Fischmeister. Convenient synthesis of cobalt nanoparticles for the hydrogenation of quinolines in water. Catalysis Science \& Technology, 2020, 10 (14), pp.4820-4826. 10.1039/d0cy00582g · hal-02928595

\section{HAL Id: hal-02928595 \\ https://hal.science/hal-02928595}

Submitted on 19 Nov 2020

HAL is a multi-disciplinary open access archive for the deposit and dissemination of scientific research documents, whether they are published or not. The documents may come from teaching and research institutions in France or abroad, or from public or private research centers.
L'archive ouverte pluridisciplinaire HAL, est destinée au dépôt et à la diffusion de documents scientifiques de niveau recherche, publiés ou non, émanant des établissements d'enseignement et de recherche français ou étrangers, des laboratoires publics ou privés. 


\section{Convenient synthesis of cobalt nanoparticles for the hydrogenation of quinolines in water}

Received 00th January 20xx, Accepted 00th January $20 x x$ DOI: $10.1039 / \times 0 \times x 00000 x$

\author{
Julien Hervochon, ${ }^{\mathrm{a}, \mathrm{b}}$ Vincent Dorcet, ${ }^{\mathrm{a}}$ Kathrin Junge, ${ }^{\mathrm{b}}$ Matthias Beller, ${ }^{\mathrm{b}}$ and Cedric Fischmeister*a
}

Easily accessible cobalt nanoparticles are prepared by hydrolysis of $\mathrm{NaBH}_{4}$ in the presence of inexpensive $\mathrm{Co}$ (II) salts. The resulting material is an efficient catalyst for the hydrogenation of quinoline derivatives in water. The activity and chemoselectivity of this catalyst are comparable to other cobalt-based heterogeneous catalysts.

\section{Introduction}

Reduction reactions and more particularly hydrogenations are ubiquitous in organic synthesis and play a major role as part of industrial processes in bulk and fine chemical synthesis. This situation will likely persist owing to the growing concerns and demands for sustainable supply of chemicals arising from biomass $^{1}$ as well as new energy carriers based on chemical hydrogen storage. ${ }^{2}$

$\mathrm{N}$-Heterocycles are important building blocks in natural and synthetic bioactive molecules among which 1,2,3,4tetrahydroquinoline is specifically valuable with numerous applications in drugs and agrochemicals. ${ }^{3}$ Recently, such molecules have also been envisioned as hydrogen reservoirs. ${ }^{4}$ As usually observed with aromatic compounds, the catalytic hydrogenation of quinoline derivatives is a challenging reaction because of potential catalyst deactivation due to coordination of quinoline reagents and tetrahydroquinoline derivatives. Various homogeneous catalysts ${ }^{5}$ have been reported for the hydrogenation of quinolines while iridium-based catalysts exhibited best performances and chemoselectivities. However, the cost of these catalysts, the sometimes necessary presence of additives and the non-recyclability of homogeneous catalysts encouraged the development of less expensive catalysts based on iron, ${ }^{6}$ manganese, ${ }^{7}$ and cobalt. ${ }^{8}$ Despite their economic interest, these catalysts still need to be improved as they display in general lower efficiency than noble metal-based catalysts and they often require expensive ligands such as pincer ligands. In the past decades, numerous heterogeneous catalysts based on noble metals have also been reported for the hydrogenation of quinoline derivatives. ${ }^{9}$ Although they usually display high

\footnotetext{
a. Univ Rennes, CNRS, ISCR (Institut des Sciences Chimiques de Rennes) - UMR 6226, ScanMat-UMS 2001, F-35000 Rennes, France.E-mail : cedric.fischmeister@univrennes1.fr

b. Leibniz-Institut für Katalyse, Albert-Einstein-Straße 29a, Rostock, 18059, “ Germany.E-mail: Matthias.Beller@catalysis.de.
}

reactivity, these catalysts suffer from low chemoselectivity hence hampering the scope of accessible product. Rare examples of chemoselective hydrogenation of quinoline make use of supported $\mathrm{Rh},{ }^{9 i} \mathrm{Au}^{9 \mathrm{v}}$ and $\mathrm{Ru}^{9 \mathrm{q}}$ nanoparticles. As for homogeneous catalysts, the search for lower cost heterogeneous catalysts is a topic of high importance in catalysis (Figure 1).

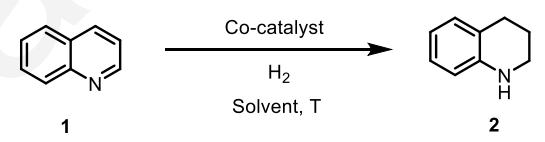

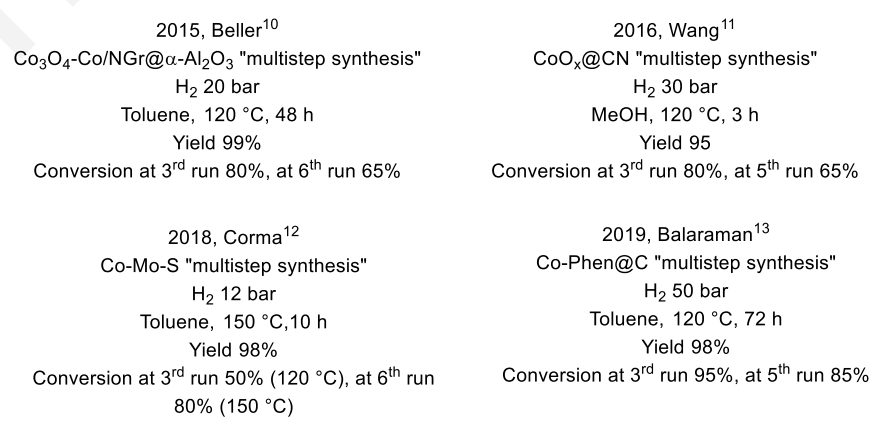

Figure 1 Overview of Co-catalyzed hydrogenation of quinoline

In 2015 , some of us reported the selective hydrogenation of heteroarenes using cobalt oxide/cobalt nanoparticles modified by nitrogen doped graphene layers on alumina. ${ }^{10}$ These catalysts efficiently hydrogenated a number of quinoline derivatives in 60-72 $\mathrm{h}$, in toluene at $120{ }^{\circ} \mathrm{C}$ and $20-30$ bar of hydrogen pressure. One year later, Wang disclosed cobalt encapsulated in $\mathrm{N}$-doped graphene layers for the hydrogenation of quinolines in 3-15 h, in methanol at $120{ }^{\circ} \mathrm{C}$ under 30 bar of hydrogen pressure. ${ }^{11}$ More recently, Corma 
reported nanolayered cobalt-molybdenum sulphides for the selective hydrogenation of quinolines. ${ }^{12}$ This catalyst operating at $120{ }^{\circ} \mathrm{C}$ and 12 bar of hydrogen pressure displayed impressive chemoselectivity as it did not hydrogenate olefins, ketone, nitrile, ester and amide functions of quinoline derivatives. However, this catalyst was moderately recyclable as conversion and yields dropped by $50 \%$ in a third run. Very recently in 2019 , Balaraman reported a Co-Phen@C catalyst for the reduction of quinolines working at $120^{\circ} \mathrm{C}$ and 50 bar of hydrogen pressure. ${ }^{13}$ Apart from cobalt, one example of heterogeneous iron catalyst was reported in 2018. ${ }^{14}$ Here, an N-doped carbon modified ironbased catalyst performed the hydrogenation of a number of quinoline derivatives at $130-150{ }^{\circ} \mathrm{C}$ under $40-50$ bar of hydroge $n$ pressure in a $\mathrm{MeOH} / \mathrm{H}_{2} \mathrm{O}$ solvent mixture. Nitrile, ester and amide moieties were not hydrogenated by this catalyst, which was recycled 6 times without loss of catalytic efficiency.

Whatever the nature of the metal (noble/non-noble), most of the known heterogeneous catalysts for this transformation require multistep synthesis or their scale up is difficult. Thus, the preparation of general and selective catalysts in a straightforward manner is stimulating for academic and industrial researchers. In this respect, metal nanoparticles attracted specific interest in recent years. For instance, naked iridium oxide nanoparticles, easily prepared from iridium trichloride and sodium hydroxide, were shown to be efficient catalysts for the hydrogenation of several quinoline derivatives at mild conditions (room temperature, 1 bar ( $\mathrm{H}_{2}$ balloon) to 60 bar). ${ }^{15}$ Similarly, Jacobi von Wangelin reported "quasi-naked" cobalt nanoparticles stabilized by olefinic substrates which were efficient for $\mathrm{C}=\mathrm{C}, \mathrm{C}=\mathrm{O}$ and $\mathrm{C}=\mathrm{N}$ bond hydrogenations in THF. ${ }^{16}$

To prepare cobalt nanoparticles in an easy and convenient manner in aqueous reaction media, the reduction of cobalt salts with sodium borohydride caught our attention. Interestingly, the activation of sodium borohydride is catalysed by numerous transition metals of which cobalt attracted most attention due to its lower cost. In fact, it is well established that hydrolysis of $\mathrm{NaBH}_{4}$ in the presence of $\mathrm{Co}(\mathrm{II})$ salt leads to various cobalt species $^{17}$ including nanoparticles. ${ }^{18}$ Inspired by these results, we developed a novel cobalt-catalysed hydrogenation of quinoline and quinoline derivatives in aqueous media. Here, we report the synthesis and application of the optimal catalyst system, which is conveniently prepared from inexpensive precursors without any additives or stabilising species.

\section{Results and discussion}

\section{Catalytic experiments}

We started our investigations with the reduction of quinoline 1 using in situ generated cobalt(0) nanoparticles. More specifically, a high-pressure reactor was successively loaded with $\mathrm{CoCl}_{2}$ (5 mol\%), $\mathrm{NaBH}_{4}(10 \mathrm{~mol} \%), \mathrm{H}_{2} \mathrm{O}(1 \mathrm{~mL})$ and quinoline 1, charged with dihydrogen and heated to temperatures between $115{ }^{\circ} \mathrm{C}$ and $130{ }^{\circ} \mathrm{C}$. As depicted in Table 1, only minor amounts of catalytic hydrogenation of $\mathbf{1}$ to $\mathbf{2}$ occurred at $20 \mathrm{bar}$ of hydrogen (Table 1 , entry 1 ). Even increasing the temperature to $130^{\circ} \mathrm{C}$ resulted in no repeatable results (Table 1 , entry 2). However, stable and quantitative reactions were achieved at $130{ }^{\circ} \mathrm{C}$ and 30 bar of hydrogen pressure (Table 1 , entry 3 ). Applying a reduced catalyst loading $(2.5 \mathrm{~mol} \%)$ still resulted in $72 \%$ conversion and excellent selectivity (Table 1, entry 4). Following these preliminary results, several other experimental parameters were varied. Literature reports on the hydrolysis of $\mathrm{NaBH}_{4}$ catalysed by $\mathrm{Co}(\mathrm{II})$ salts clearly established that the $\mathrm{Co}(\mathrm{II}) / \mathrm{NaBH}_{4}$ ratio is a key parameter determining the nature of the generated cobalt species. ${ }^{16}$ Hence, the hydrogenation of quinoline was studied in the presence of different amounts of $\mathrm{NaBH}_{4}$ showing an interesting influence on the reaction selectivity. The reaction could be performed with only $5 \%$ of $\mathrm{NaBH}_{4}$ but again the repeatability of the reaction was not fully satisfactory leading to $80 \%$ to full conversions (Table 1, entry 6). Notably, increasing the amount of sodium borohydride to 20 mol\% and to $50 \mathrm{~mol} \%$, respectively resulted in a different reduction pathway leading to product $\mathbf{3}$ arising from the hydrogenation of the carbon-ring (Table 1, entries 7-8). Apparently, different kinds of active cobalt nanoparticles are formed depending on the amount of sodium borohydride. This selectivity issue has already been mentioned with several heterogeneous catalysts with sometimes trace amounts of fully hydrogenated product. ${ }^{19}$ Notably, the reaction was successfully scaled-up to $2 \mathrm{~g}$ of quinoline using best experimental conditions (Table 1, entry 9).

Table 1 Catalytic hydrogenation of quinoline in the presence of cobalt nanoparticles ${ }^{a}$

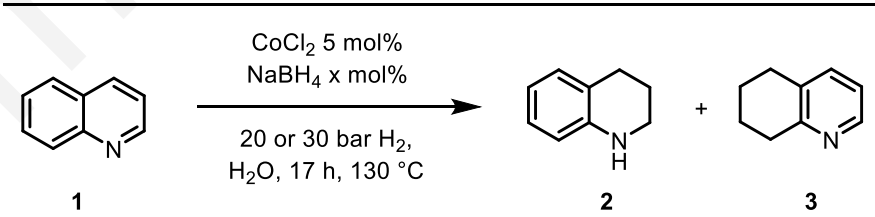

\begin{tabular}{|c|c|c|c|c|c|c|}
\hline Entry & $\begin{array}{c}\mathrm{NaBH}_{4} \\
(\mathrm{~mol} \%)\end{array}$ & $\begin{array}{c}\mathrm{P}\left(\mathrm{H}_{2}\right) \\
(\mathrm{bar})\end{array}$ & $\begin{array}{c}\mathrm{T} \\
\left({ }^{\circ} \mathrm{C}\right)^{b}\end{array}$ & $\begin{array}{c}\text { Conv. } \\
(\%)^{\mathrm{c}}\end{array}$ & $\mathbf{2}(\%)^{c}$ & $\mathbf{3}(\%)^{c}$ \\
\hline 1 & 10 & 20 & 115 & 10 & 10 & 0 \\
\hline 2 & 10 & 20 & 130 & $84-99$ & $84-99$ & 0 \\
\hline 3 & 10 & 30 & 130 & 100 & 100 & 0 \\
\hline $4^{d}$ & 10 & 30 & 130 & 72 & 72 & 0 \\
\hline 5 & 2.5 & 30 & 130 & 36 & 36 & 0 \\
\hline 6 & 5 & 30 & 130 & $79-\geq 99$ & $79-\geq 99$ & 0 \\
\hline 7 & 20 & 30 & 130 & $\geq 99$ & 82 & 8 \\
\hline 8 & 50 & 30 & 130 & $>99$ & 78 & 22 \\
\hline $9^{\mathrm{e}}$ & 10 & 30 & 130 & 100 & 100 & 0 \\
\hline
\end{tabular}

${ }^{a}$ Conditions: Quinoline $(0.100 \mathrm{~g} ; 0.78 \mathrm{mmol}), \mathrm{CoCl}_{2}(0.038 \mathrm{mmol} ; 5 \mathrm{~mol} \%), \mathrm{NaBH}_{4}$ (2.95 mg, $10 \mathrm{~mol} \%), \mathrm{H}_{2} \mathrm{O}(1 \mathrm{~mL}), 17 \mathrm{~h}$. ${ }^{b}$ Oil bath temperature. ${ }^{c}$ Conversion determined by ${ }^{1} \mathrm{H} \mathrm{NMR}^{d}{ }^{d} \mathrm{CoCl}_{2}(2.5 \mathrm{~mol} \%)$. All experiments were done twice. ${ }^{\mathrm{e}} 2 \mathrm{~g}$ scale of quinolone.

The activation period corresponding to the amount of time between the addition of water to $\mathrm{CoCl}_{2} / \mathrm{NaBH}_{4}$ and quinoline was also considered and studied as a key parameter. As the reduction of cobalt salts by $\mathrm{NaBH}_{4}$ is a fast reaction, a study was conducted with short activation periods. The initial assumption was verified as an increase in conversion was observed upon increasing the activation period to 6 minutes. Further extension 
Table 2 Co-nanoparticles catalyzed hydrogenations of quinoline: Influence of the activation period $^{a}$<smiles>c1ccc2ncccc2c1</smiles>

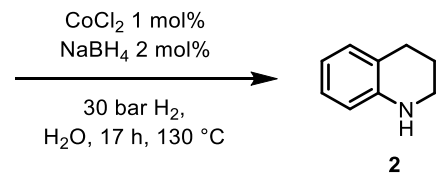

2

\begin{tabular}{|c|c|c|c|}
\hline Entry & $\mathrm{t}(\min )$ & ${\text { Conv. }(\%)^{\mathrm{b}}}$ & $\mathbf{2}(\%)^{b}$ \\
\hline 1 & 0 & 15 & 15 \\
\hline 2 & 3 & 19 & 19 \\
\hline 3 & 6 & 23 & 23 \\
\hline 4 & 8 & 16 & 16 \\
\hline 5 & 10 & 14 & 14 \\
\hline
\end{tabular}

a Conditions: Quinoline (0.100 g; $0.78 \mathrm{mmol}), \mathrm{CoCl}_{2}$ (0.038 mmol; $1 \mathrm{~mol} \%$ ); $\mathrm{NaBH}_{4}(2 \mathrm{~mol} \%), \mathrm{H}_{2} \mathrm{O}(1 \mathrm{~mL}), \mathrm{H}_{2}\left(30\right.$ bar), $130{ }^{\circ} \mathrm{C}, 17 \mathrm{~h}$. ${ }^{b}$ Conversion and yield determined by ${ }^{1} \mathrm{H} \mathrm{NMR}$

of this activation period led to lower performances indicating the evolution of the catalytic species into non- or less reactive species (Table 2). The involvement of quinoline and/or tetrahydroquinoline in the stabilisation of cobalt species should also not be ruled out.

Next, we examined the influence of various cobalt(II) precursors. Apart from cobalt(II) acetylacetonate which was less suitable for this reaction, it is worth noting that the less toxic $\left(\mathrm{NH}_{4}\right)_{2} \mathrm{Co}\left(\mathrm{SO}_{4}\right)_{2} \cdot 6 \mathrm{H}_{2} \mathrm{O}$ was found as effective as $\mathrm{CoCl}_{2}$ (Table 3 , entry 3 ) and was used in some examples of the substrate scope study (vide infra).

Table 3 Catalytic hydrogenations of quinoline: Evaluation of $\mathrm{Co}$ (II) precursors ${ }^{a}$

\begin{tabular}{|c|c|c|c|}
\hline Entry & Catalyst & Conv. (\%) $)^{\mathrm{b}}$ & $\mathbf{2}(\%)$ \\
\hline 1 & $\mathrm{CoCl}_{2}(5 \mathrm{~mol} \%)$ & 100 & 100 \\
\hline 2 & $\mathrm{Co}(\mathrm{acac})_{2}(5 \mathrm{~mol} \%)$ & $84^{c}$ & 84 \\
\hline 3 & $\left(\mathrm{NH}_{4}\right)_{2} \mathrm{Co}\left(\mathrm{SO}_{4}\right)_{2} \cdot 6 \mathrm{H}_{2} \mathrm{O}(5 \mathrm{~mol} \%)$ & 100 & 100 \\
\hline 4 & $\mathrm{CoCl}_{2} \cdot 6 \mathrm{H}_{2} \mathrm{O}(5 \mathrm{~mol} \%)$ & 100 & 100 \\
\hline
\end{tabular}

a Conditions: Quinoline (0.100 g, $0.78 \mathrm{mmol}), \mathrm{NaBH}_{4}(10 \mathrm{~mol} \%), \mathrm{H}_{2} \mathrm{O}(1 \mathrm{~mL})$, $\mathrm{H}_{2}$ (30 bar), $130{ }^{\circ} \mathrm{C}, 17 \mathrm{~h} .{ }^{b}$ Conversion determined by ${ }^{1} \mathrm{H}$ NMR. ${ }^{c}$ Average of 3 reactions $(79 \%, 85 \%, 89 \%)$. All reactions were done two or three times.

The recycling of the Co-Nps was evaluated by means of consecutive quinoline hydrogenation runs taking advantage of the magnetic properties of the in situ formed Co-Nps allowing for a facile separation of the heterogeneous catalyst (Figure 2).

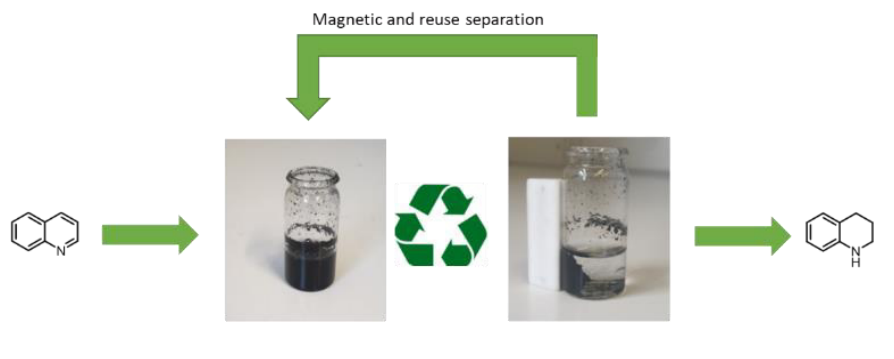

Figure 2 Separation of magnetic cobalt particles

After a first run performed under the previously optimised conditions, the reaction mixture was extracted with ethyl acetate and the aqueous phase containing the cobalt catalyst was reloaded with sodium borohydride, quinoline and stirred at $130{ }^{\circ} \mathrm{C}$ for $17 \mathrm{~h}$ under 30 bar of dihydrogen. Following this procedure, it was possible to perform three runs with excellent conversion and selectivity after which a quick drop in conversion was observed without deterioration of selectivity (Figure 3). This result is attributed to the deactivation of the catalyst as a black layer accumulated with time over the vial walls. This assumption was confirmed by analysing the reaction mixture arising from a recycling test in which the vial walls were coated by a black solid. Indeed, cobalt could not be detected by TEM/EDS analyses of this reaction mixture indicating that all the cobalt was coated onto the vial walls and was catalytically inactive. To understand this catalyst deactivation, another recycling experiment was performed in which the aqueous reaction mixture was separated from the insoluble material after the first run.

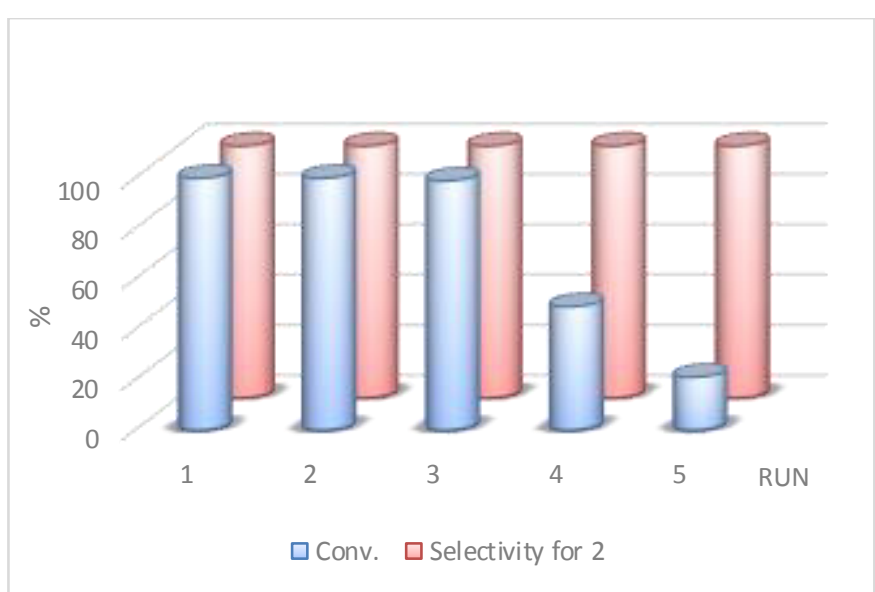

Figure 3 Catalytic hydrogenations of quinoline: Recycling of cobalt catalyst

The generated black solid was washed with water and a second run was started under standard conditions giving a lower conversion of only $50 \%$. This observation is most likely explained by the removal of soluble catalytic cobalt species. ${ }^{18}$

Next, the scope and limitations of the present catalyst was investigated by the hydrogenation of a broad range of substrates diversely substituted on the phenyl- or pyridyl-ring 
(Table 4). The substitution of the pyridyl-ring by alkyl or aryl groups led to the desired products in good yields with the exception of 3-methylquinoline where a mixture of the corresponding tetrahydroquinoline along with 3-methyl5,6,7,8-tetrahydroquinoline was formed (Table 4, entry 2). On the contrary, quinolines substituted at the pyridyl-ring by bromine and chloride atoms were unreactive even at higher temperature $\left(150{ }^{\circ} \mathrm{C}\right.$; Table 4 , entries $\left.4-5\right)$. However, to the best of our knowledge, such reactions have not been reported in the literature and it should be mentioned that no dehalogenation was observed with the brominated reagents as reported for Pdnanoparticules..$^{20}$ In case of the chloro-substituted derivative dechlorination occurred to a small extent $(\sim 5 \%)$. Nevertheless, these failures provide some hints on the reaction mechanis m indicating that $\mathrm{N}$-coordination of quinolone to the catalyst is necessary. Interestingly, the catalyst was found much less sensitive to the substitution pattern on the phenyl ring. Indeed, alkyl-, alkoxy- and halo-substituted products were obtained in good to high yields (Table 4, entries 6-12). The chemoselectivity of the catalyst was investigated using either functionalized reagents or mixtures of reagents. Indeed, the selective hydrogenation of quinoline derivatives in the presence of an ester group or internal carbon-carbon double bonds was demonstrated (Table 4, entries 14 and 17).

Table 4 Scope and limitations ${ }^{a}$

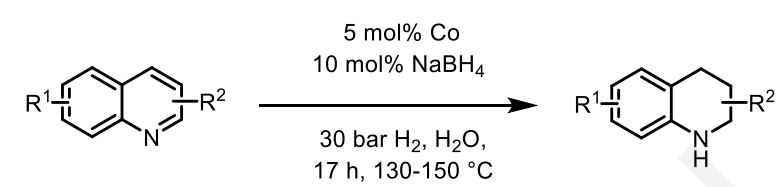

Entry Substrate

17<smiles>COC(=O)c1ccc2ncccc2c1</smiles><smiles>c1ccccc1</smiles>

150<smiles>COC(=O)c1ccc2c(c1)CCN2</smiles>

150<smiles>c1ccc2c3c(ccc2c1)CCCN3</smiles>

130

150<smiles>c1cnc2c(c1)ccc1cccnc12</smiles><smiles>[TeH]</smiles><smiles>c1ccc2nccnc2c1</smiles><smiles>c1ccc2cnccc2c1</smiles><smiles>c1ccc2[nH]cnc2c1</smiles><smiles>C1=CC2Cc3ccccc3NC2C=C1</smiles>

150<smiles>c1ccc2c(c1)NCCN2</smiles>

150<smiles>c1ccc2c(c1)CCNC2</smiles>

150<smiles></smiles>

>99 (99)

$>99$ (97)<smiles>CCCCc1ccnc2ccc(OC)cc12</smiles><smiles>CC1=CCC(C(C)C)CC1</smiles>

>99/>99<smiles>OCc1ccc2c(c1)CCCN2</smiles>

$>99$ (80)

$>99 / 98$<smiles>CC(O)c1ccccc1</smiles>

$>99$ (73)

$>99$ (73)

$>99$ (62)

$>99$ (95)

0

0

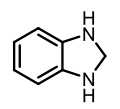

a Substrate $(0.5 \mathrm{mmol}), \mathrm{NaBH}_{4}(1.90 \mathrm{~g}, 0.005 \mathrm{mmol}), \mathrm{CoCl}_{2}(5 \mathrm{~mol} \%), \mathrm{H}_{2} \mathrm{O}(1 \mathrm{~mL})$, $\mathrm{H}_{2}, 30$ bar, $\mathrm{t}=17 \mathrm{~h}, \mathrm{~T}=$ oil bath temperature. ${ }^{\mathrm{b}}$ Conversion determined by ${ }^{1} \mathrm{H} \mathrm{NMR}$ c Isolated yields in parentheses. ${ }^{d}(\mathrm{NH} 4) 2 \mathrm{Co}(\mathrm{SO} 4) 2.6 \mathrm{H} 2 \mathrm{O}(5 \mathrm{~mol} \%)$; ${ }^{\mathrm{e}} 40 \mathrm{bar} \mathrm{H}_{2}$. 
However, as exemplified in entry 14 , the catalyst also selectively hydrogenated a terminal carbon-carbon double bond. The selective reduction of quinolines bearing carbonylfunctionalities was investigated, as only very few catalysts for such transformations have been reported. As evidenced in entries 15-17, the formyl- and keto- group were readily hydrogenated while the ester group was not reduced vide supra. The scope of the reaction was further extended to other $\mathrm{N}$-heterocyclic compounds that were all converted with high conversion leading to the desired products in good to excellent yields except for isoquinoline and $1 \mathrm{H}$-benzoimidazole (Table 5 , entries 18-24). As explained earlier, the less toxic $\left(\mathrm{NH}_{4}\right)_{2} \mathrm{Co}\left(\mathrm{SO}_{4}\right)_{2} .6 \mathrm{H}_{2} \mathrm{O}$ precursor was employed in some examples and found to be a suitable cobalt precursor, too (Table 4, entries 3, 14, 21).

\section{Characterisation of the catalyst}

With these results in hands, we turned our attention to the nature of the catalyst. As mentioned in the introduction, the hydrolysis of $\mathrm{NaBH}_{4}$ in the presence of $\mathrm{CoCl}_{2}$ is a very complex process likely to generate several cobalt species. Several parameters such as the ratio $\mathrm{CoCl}_{2} / \mathrm{NaBH}_{4}$ or the rate of hydrolysis influence this process. In general, we applied for the catalytic experiments a catalyst prepared by hydrolysis of $\mathrm{NaBH}_{4}$ in the presence of $\mathrm{CoCl}_{2}$ in a 2/1 ratio. The resulting dark suspension in water was analysed by Transmission Electron Microscopy and Energy Dispersive Spectrometry. As shown in Figure 4 , the analysed material consisted essentially of nanosheet structures (Fig 4, a, b \& c) containing cobalt, as demonstrated by EDS analyses (See SI). Interestingly and despite the absence of any stabilizers, it was also possible to identify cobalt nanoparticles by HRTEM (Fig 4, d). We were also interested in the stabilty of the formed nano-sheet structures during catalysis. For this reason, a reaction mixture arising from the hydrogenation of quinoline under standard conditions was also analysed by TEM. As displayed in Figure 5, this reaction mixture yet consisted in amorphous particles but of bigger size and it was no longer possible to identify crystalline particles. Consequently, the contribution of cobalt nanoparticles to the overall catalytic activity cannot be discarded in the first run, but other "true" heterogeneous cobalt species are also involved as evidenced by the recycling test. However, it is worth noting that cobalt nanoparticles prepared from organometallic cobalt complexes and sodium borohydride in isopropanol were inactive for the hydrogenation of quinoline. ${ }^{21}$
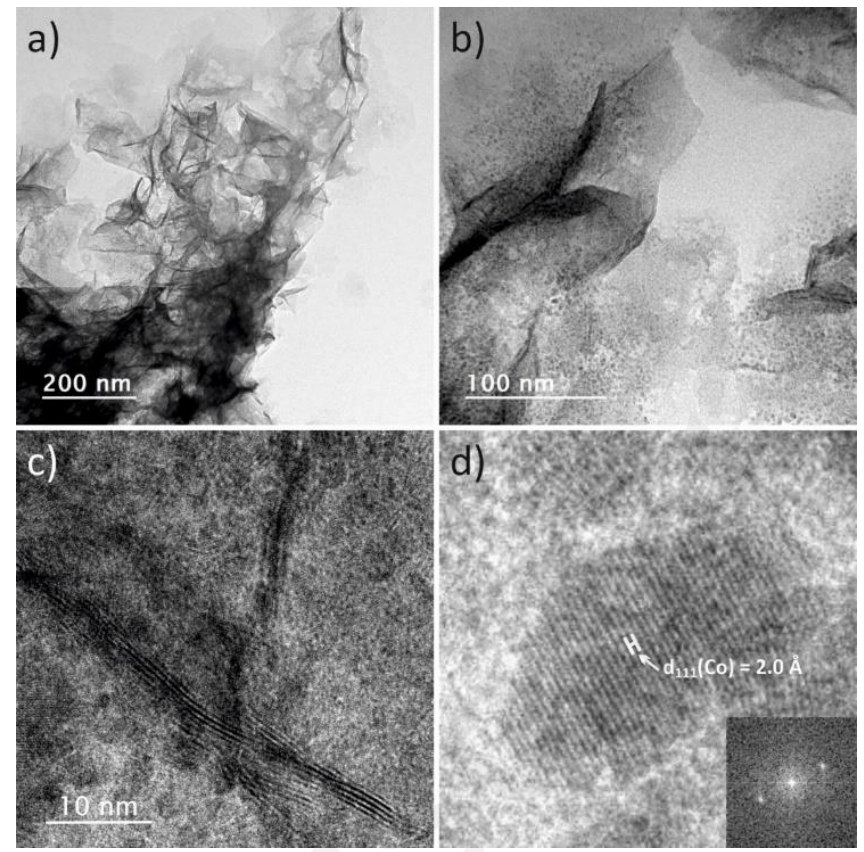

Figure 4:a, b, c: TEM images of catalytic material; d: HRTEM image of crystalline particle with corresponding Fast Fourier Transform

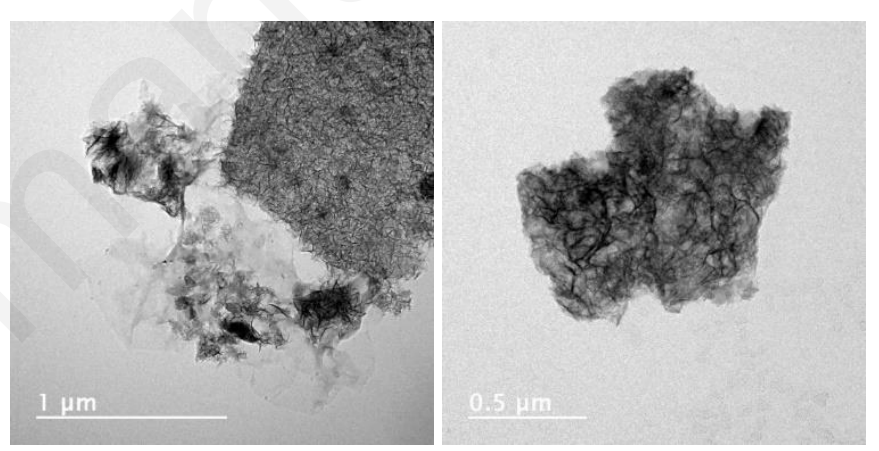

Figure 5 TEM images of particles suspended in a reaction mixture

\section{Conclusions}

In conclusion, we have prepared catalytically active cobalt nanoparticles by hydrolysis of $\mathrm{NaBH}_{4}$ in the presence of $\mathrm{Co}(\mathrm{II})$ salts. The catalyst consists initially of a mixture of cobalt nanoparticles and cobalt-containing nanosheets and evolves to bigger Co particles upon reuse. The activity and chemoselectivity of this catalyst are comparable to other welldefined heterogeneous catalyst made of cobalt only. ${ }^{22}$ Notably, this catalyst is easily prepared from inexpensive cobalt precursors and readily accessible to synthetic chemists. Furthermore, the catalyst preparation does not need any additives and to the contrary of many heterogeneous catalysts, it is prepared and used in water hence making the overall process convenient and more environmentally friendly.

\section{Conflicts of interest}

"There are no conflicts to declare". 


\section{Acknowledgements}

The authors acknowledge the Région Bretagne (ARED) for a grant to $\mathrm{JH}$.

\section{Notes and references}

1 (a) P. N. R. Vennestrom, C. M. Osmundsen, C. H. Christensen and E. Taarning, Angew. Chem. Int. Ed., 2011, 50, 10502; (b) P. J. Deuss, K. Barta and J. G. de Vries, Catal. Sci. Technol., 2014, 4, 1174; (c) M. J. Clement, A. Corma and S. Iborra, Green Chem., 2014, 16, 516; (d) L. T. Mika, E. Cséfalvay and A. Németh, Chem. Rev., 2018, 118, 505.

2 (a) R. H. Crabtree, Energy Environ. Sci., 2008, 1, 134; (b) U. Eberle, M. Felderhoff and F. Schuth, Angew. Chem. Int. Ed., 2009, 48, 6608; (c) N. Armaroli and V. Balzani, ChemSusChe m, 2011, 4, 21-36; (d) K. Sordakis, C. Tang, L. K. Vogt, H. Junge, P. J. Dyson, M. Beller and G. Laurenczy, Chem. Rev., 2018, 118, 372.

3 (a) V. Sridharan, P. A. Suryavanshi and J. Carlos Menendez, Chem. Rev., 2011, 111, 7157; (b) I. Muthukrishnan, V. Sridharan and J. Carlos Menendez, Chem. Rev., 2019, 119, 5057.

4 (a) D. Teichmann, W. Arlt, P. Wasserscheid and R. Freymann, Energy Environ. Sci., 2011, 4, 2767; (b) R. Yamaguchi, C. Ikeda, Y. Takahashi and K. Fujita, J. Am. Chem. Soc., 2009, 131, 8410; (c) C. Deraedt, R. Ye, W. T. Ralston, F. D. Toste and G. A. Somorjai, J. Am. Chem. Soc., 2017, 139, 18084; (d) S. Wang, H. Huang, C. Bruneau and C. Fischmeister, ChemSusChem, 2019, 12, 2350.

5 For hydrogenation reactions, see: (a) R. A. Sanchez-Delgado and E. Gonzalez, Polyhedron, 1989, 8, 1431; (b) W. B. Wang, S. M. Lu, P. Y. Yang, X. W. Han and Y. G. Zhou, J. Am. Chem. Soc., 2003, 125, 10536; (c) H. Zhou, Z. Li, Z. Wang, T. Wang, L. $\mathrm{Xu}, \mathrm{Y}$. He, Q.-H. Fan, J. Pan, L. Gu and A. S. C. Chan, Angew. Chem., Int. Ed., 2008, 47, 8464; (d) H. Li, J. Jiang, G. Lu, F. Huang and Z.-X. Wang, Organometallics, 2011, 30, 3131; (e) G. E. Dobereiner, A. Nova, N. D. Schley, N. Hazari, S. J. Miller, O. Eisenstein and R. H. Crabtree, J. Am. Chem. Soc., 2011, 133 7547; (f) J. Wu, J. H. Barnard, Y. Zhang, D. Talwar, C. M. Robertson and J. Xiao, Chem. Commun., 2013, 49, 7052; (g) X.F. Cai, W.-X. Huang, Z.-P. Chen and Y.-G. Zhou, Chem. Commun., 2014, 50, 9588; (h) Y. Wang, Z. Huang, X. Leng, H. Zhu, G. Liu and Z. Huang, J. Am. Chem. Soc., 2018, 140, 4417; (i) A. Vivancos, M. Beller, M. Albrecht, ACS Catal., 2018, 8, 17. For transfer hydrogenation reactions, see: (j) C. Wang, C. Li, X. Wu, A. Pettman and J. Xiao, Angew. Chem. Int. Ed., 2009, 48, 6524; (k) L. Zhang, R. Qiu, X. Xue, Y. Pan, C. Xu, H. Li and L. Xu, Adv. Synth. Catal., 2015, 357, 3529; (I) I. D. Alshakova, B. Gabidullin and G. I. Nikonov, ChemCatChem, 2018, 10, 4860.

6 S. Chakraborty, W. B. Brennessel and W. D. Jones, J. Am. Chem. Soc., 2014, 136, 8564.

7 (a) V. Papa, Y. Cao, A. Spannenberg, K. Junge, M. Beller, Nature. Catal. 2020, 10.1038/s41929-019-0404-6; (b) Y. Wang, Z Shao, G. Li, Y. Ian, Q. Liu, J. Am. Chem. Soc. 2019, 141, 17337.

8 (a) R. Xu, S. Chakraborty, H. Yuan and W. D. Jones, ACS Catal., 2015, 5, 6350; (b) R. Adam, J. R. Cabrero-Antonino, A. Spannenberg, K. Junge, R. Jackstell and M. Beller, Angew. Chem., Int. Ed., 2017, 56, 3216; (c) J. R. Cabrero-Antonino, R. Adam, K. Junge, R. Jackstell and M. Beller, Catal. Sci. Technol., 2017, 7, 1981.

9 Selected references for Pd catalysts: (a) N. Hashimoto, Y. Takahashi, T. Hara, S. Shimazu, T. Mitsudome, T. Mizugaki, K. Jitsukawa and K. Kaneda, Chem. Lett., 2010, 39, 832; (b) R. Rahi, M. Fang, A. Ahmed and R. A. Sanchez-Delgado, Dalton Trans., 2012, 41, 1449; (c) H. Mao, J. Ma, Y. Liao, S. Zhao and
X. Liao, Catal. Sci. Technol., 2013, 3, 1612; (d) M. Guo, C. Li and Q. Yang, Catal. Sci. Technol., 2017, 7, 2221.

Selected references for Rh catalysts: (e) M. Campanati, M. Casagrande, I. Fagiolino, M. Lenarda, L. Storaro, M. Battagliarin and A. Vaccari, J. Mol. Catal. A: Chem., 2002, 184, 267; (f) V. Mévellec and A. Roucoux, Inorg. Chim. Acta, 2004, 357, 3099; (g) G.-Y., Fan and J. Wu, Catal. Commun., 2013, 31, 81; (h) M. Niu, Y. Wang, P. Chen, D. Du, J. Jiang and Z. Jin, Catal. Sci. Technol., 2015, 5, 4746; (i) A. Karakulina, A. Gopakumar, I. Akçok, B. L. Roulier, T. LaGrange, S. Katsyuba, S. Das and P. J. Dyson, Angew. Chem. Int. Ed., 2016, 55, 292; (j) A. Karakulina, A. Gopakumar, Z. Fei, andP. J. Dyson, Catal. Sci. Technol., 2018, 8, 5091.

Selected references for $R u$ catalysts: (k) C. Bianchini, V. Dal Santo, A. Meli, S. Moneti, M. Moreno, W. Oberhauser, R. Psaro, L. Sordelli and F. A. Vizza, J. Catal., 2003, 213, 47; (I) Y.P. Sun, H.-Y. Fu, D.-I. Zhang, R.-X. Li, H. Chen and X.-J. Li, Catal. Commun., 2010, 12, 188; (m) M. Fang, N. Machalaba, and R. A. Sanchez-Delgado, Dalton Trans., 2011, 40, 10621; (n) L. Zhang, X. Wang, Y. Xue, X. Zeng, H. Chen, R. Li and S. Wang, Catal. Sci.Technol., 2014, 4, 1939; (o) H.-Y. Jiang and X.-X. Zheng, Catal. Sci. Technol., 2015, 5, 3728; (p) M. Tang, J. Deng, M. Li, X. Li, H.Li, Z. Chen and Y. Wang, Green Chem., 2016, 18, 6082; (q) B. Sun, D. Carnevale and G. Süss-Fink, J. Organomet. Chem., 2016, 821, 197; ( $r$ ) T.-N. Ye, J. Li, M. Kitano and H. Hosono, Green Chem., 2017, 19, 749; (s) H. Konnerth and M. H. G. Prechtl, Green Chem., 2017, 19, 2762.

Selected references for iridium catalysts: (t) P. Barbaro, L. Gonsalvi, A. Guerriero and F. Liguori, Green Chem., 2012, 14, 3211; (u) Y.-G. Ji, K. Wei, T. Liu, L. Wu and W.-H. Zhang, Adv. Synth. Catal., 2017, 359, 933.

For Gold catalysts: (v) D. Ren, L. He, L. Yu, R. S. Ding, Y. M. Liu, Y. Cao, H. Y. He and K. N. Fan, J. Am. Chem. Soc., 2012, 134, 17592.

10 F. Chen, A.-E. Surkus, L. He, M.-M. Pohl, J. Radnik, C. Topf, K. Junge and M. Beller, J. Am. Chem. Soc., 2015, 137, 11718.

11 Z. Wei, Y. Chen, J. Wang, D. Su, M. Tang, S. Mao and Y. Wang, ACS Catal., 2016, 6, 5816.

12 I. Sorribes, L. Liu, A. Doménech-Carbó and A. Corma, ACS Catal., 2018, 8, 4545.

13 G. Jaiswal, M. Subaramanian, M. K. Sahoo and E. Balaraman, ChemCatChem, 2019, 11, 2449.

14 B. Sahoo, C. Kreyenschulte, G. Agostini, H. Lund, S. Bachmann, M. Scalone, K. Junge and M. Beller, Chem. Sci., 2018, 9, 8134.

15 Y.-G. Ji, K. Wei, T. Liu, L. Wu and W.-H. Zhang, Adv. Synth. Catal., 2017, 359, 933.

16 (a) S. Sandl, F. Schwarzhuber, S. Pöllath, J. Zweck and A. Jacobi von Wangelin, Chem. Eur. J., 2018, 24, 3403; (b) P. Büschelberger, E. Reyes-Rodriguez, C. Schöttle, J. Treptow, C. Feldmann, A. Jacobo von Wangelin and R. Wolf, Catal. Sci. Technol., 2018, 8, 2648.

17 (a) U. B. Demerci and P. Miele, Phys. Chem. Chem. Phys., 2010, 12, 14651; (b) U. B. Demerci, O. Akdim, J. Andrieux, J. Hannaeur, R. Chamoun and P. Miele, Fuel Cells, 2010, 10, 335.

18 (a) G. N. Glavee, K. J. Klabunde, C. M. Sorensen and G. C. Hadjipanayis, Langmuir, 1993, 9, 162; (b) X. Liang and L. Zhao, RSC Advances, 2012, 2, 5485(c) P. Brack, S. E. Dann and K. G. Upul Wijayantha, Energy Sci. Eng., 2015, 3, 174; (d) C. Che, H. Huang, Z. Zhang, X.-Q. Dong and X. Zhang, Chem. Commun., 2017, 53, 4612

19 (a) S. Zhang, Z. Xia, T. Ni, Z. Zhang, Y. Ma and Y. Qu, J. Catal. 2018, 359, 101; (b) $\mathrm{H}-\mathrm{y}$ Jiang, J. $\mathrm{Xu}$ and B. Sun, App. Organometal. Chem., 2018, 32, 4260; (c) X. Wang, W. Chen, L. Zhang, T. Yao, W. Liu, Y. Lin, H. Ju, J. Dong, L. Zheng, W. Yan, X. Zheng, Z. Li, X. Wang, J. Tang, D. He, Y. Wang, Z. Deng, Y. Wu and Y. Li, J. Am. Chem. Soc., 2017, 139, 9419.

20 Y. Zhang, J. Zhu, Y.-T. Xia, X.-T. Sun and L. Wu, Adv. Synth. Catal., 2016, 358, 3039. 
21 P. Puylaert, A. Dell'Acqua, F. El Ouahabi, A. Spannenberg, T. Roisnel, L. Lefort, S. Hinze, S. Tin and J. G. de Vries, Catal. Sci. Technol., 2019, 9, 61.

22 The selectivity is not as good as that reported by Corma with a cobalt-molybdenum catalyst, ref 12 . 